\title{
$O$ atendimento à saúde de homens: estudo qualitativo em quatro estados brasileiros
}

I ${ }^{1}$ Romeu Gomes, ${ }^{2}$ Lilia Blima Schraiber, ${ }^{3}$ Márcia Thereza Couto, ${ }^{4}$ Otávio Augusto de Andrade Valença, ${ }^{5}$ Geórgia Sibele Nogueira da Silva, ${ }^{6}$ Wagner dos Santos Figueiredo, ${ }^{7}$ Rosana Machin Barbosa, ${ }^{8}$ Thiago Félix Pinheiro I

Resumo: O objetivo deste estudo é analisar os sentidos atribuídos por usuários homens ao atendimento que lhes é prestado no âmbito da atenção básica à saúde, buscando subsidiar a construção de indicadores qualitativos de satisfação em relação ao uso desses serviços por usuários masculinos. Trata-se de uma pesquisa qualitativa, envolvendo entrevistas semiestruturadas com 201 usuários de quatro estados brasileiros. A análise se baseia no método de interpretação de sentidos, ancorando-se em princípios hermenêutico-dialéticos. Em termos de resultados, os usuários apontam critérios para avaliar positivamente os serviços, tomando como referências um atendimento comunicativo e atencioso, que lhes faça algo e que revele prontidão. Conclui-se que os homens usuários idealizam e reivindicam uma dada forma de atendimento considerada boa e que, a princípio, poderia servir para se discutir o atendimento de mulheres também. Entretanto, em razão da socialização que homens e mulheres experimentam, são reforçadas as diferenças entre o ser usuário homem e ser usuário mulher. Por outro lado, tanto no que tange aos profissionais quanto aos usuários, essa mesma segmentação por gênero pode contribuir para que se acirrem as impossibilidades de se lidar com as especificidades de homens e mulheres, em termos de demandas da saúde.

> Palavras-chave: Satisfação de usuários; saúde do homem; homens; atenção primária à saúde.

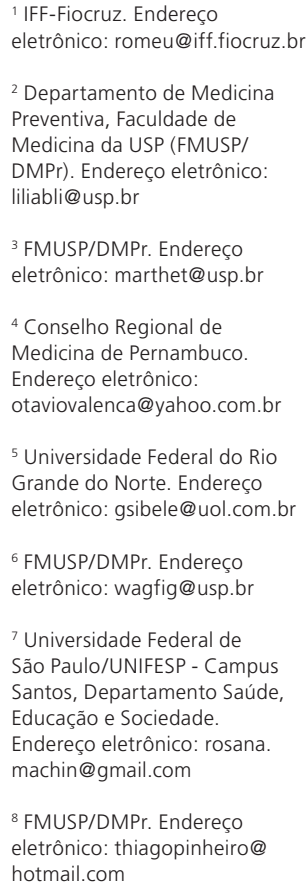

${ }^{1}$ IFF-Fiocruz. Endereço eletrônico: romeu@iff.fiocruz.br

2 Departamento de Medicina Preventiva, Faculdade de Medicina da USP (FMUSP/ DMPr). Endereço eletrônico: liliabli@usp.br

${ }^{3}$ FMUSP/DMPr. Endereço eletrônico: marthet@usp.br

${ }^{4}$ Conselho Regional de Medicina de Pernambuco. Endereço eletrônico: otaviovalenca@yahoo.com.br

${ }^{5}$ Universidade Federal do Rio Grande do Norte. Endereço eletrônico: gsibele@uol.com.br

${ }^{6}$ FMUSP/DMPr. Endereço eletrônico: wagfig@usp.br

${ }^{7}$ Universidade Federal de São Paulo/UNIFESP - Campus Santos, Departamento Saúde, Educação e Sociedade. Endereço eletrônico: rosana. machin@gmail.com

${ }^{8}$ FMUSP/DMPr. Endereço eletrônico: thiagopinheiro@ hotmail.com

Recebido em: 18/12/2009. Aprovado em: 17/05/2010. 


\section{Introdução}

Nos últimos anos, vem sendo focalizada a relação dos homens com os serviços de atenção primária à saúde. Nessa relação, destaca-se o fato de a presença dos homens nesses serviços ser menor do que a das mulheres (FIGUEIREDO, 2005; GOMES, 2007; PINHEIRO et al., 2002). Junto a isso, problematiza-se o fato de que o não reconhecimento da singularidade dos homens por parte dos próprios serviços de saúde pode trazer dificuldades em incorporar esses sujeitos como um protagonista de seus cuidados (GOMES et al., 2011). Caminhar nessa lógica pode contribuir para que os serviços de saúde melhor atendam às demandas de seus usuários masculinos. A escuta dos próprios sujeitos pode ser um dos caminhos a ser trilhado para essa adequação, possibilitando conhecer a satisfação ou insatisfação desses usuários em relação ao atendimento que lhes é prestado.

$\mathrm{Na}$ literatura, a satisfação - além de ser vista como um indicador sensível da qualidade do serviço prestado - vem sendo considerada como uma estratégia para maior adequação dos serviços a suas demandas (BOSI; AFFONSO, 1998; CASTILLO et al., 2007; ESPERIDIÃO; TRAD, 2005). Conceitualmente, é entendida como percepção de qualidade relacionada a um serviço prestado e não a um bem de consumo (CASTILLO et al., 2007). Possivelmente, a percepção do usuário acerca do serviço, além de se relacionar com suas expectativas, expressa o modo como ele se apropria da cultura dominante, o que influenciará seus discursos e argumentos acerca do que julga ser um bom serviço ou uma boa prática de atenção à sua saúde. Além disso, considera-se que a satisfação se relaciona a vários fatores, tais como: estilo de vida, experiências prévias, expectativas de futuro, valores individuais e valores sociais, remetendo a princípios de direitos individuais e de cidadania (BOSI; AFFONSO, 1998).

Uma das importantes referências teórico-metodológicas para se estudar a satisfação dos usuários é a Teoria Centrada na Satisfação do Paciente (ARAGON, 2003; ARAGON; GESELL, 2003). A expressão "paciente" costuma ser substituída por alguns autores por usuários, uma vez que pode ser associada à ideia de ausência de poder e de independência em relação ao terapeuta (VAITSMAN; ANDRADE, 2005). Nessa teoria, destaca-se que a satisfação ou a insatisfação podem ocorrer por conta da relação que se estabelece entre a expectativa do usuário e a eficácia/eficiência do atendimento. No trato dessa relação, considera- 
se o atendimento inicial, o tempo de espera e quem lhe presta o atendimento (ARAGON, 2003; ARAGON; GESELL, 2003).

Considerando-se os descritores de ciências da saúde (DeCS/MeSH) na base Medline, em um estudo de 2008 (GOMES et al., 2009), foram encontrados mais de 1.510 artigos com a associação entre os descritores satisfação do usuário ou satisfação do paciente com atenção básica à saúde. Esse mesmo estudo, ao refinar a busca com os descritores "saúde do homem" e/ou "homens", não identificou nenhum artigo.

$\mathrm{Na}$ biblioteca Scielo, em 22 de maio de 2009, ao se fazer a pesquisa de artigos por assunto, foram encontrados os seguintes resultados: para "satisfação" e "atenção primária", um artigo; para "satisfação" e "atenção básica", dois artigos; "satisfação" e "PSF" (Programa Saúde da Família), 10 artigos. Em dois desses artigos, predominava a discussão sobre usuários (OLIVEIRA; BORGES, 2008; TRAD et al., 2002). Associando-se esses assuntos à palavra-chave "homens", nenhum artigo foi encontrado.

Essas buscas apontam para a necessidade de se desenvolver estudos acerca da temática em questão, para que se possa melhor conhecer as expectativas masculinas e adequar os serviços às demandas dos homens. Considerando esses aspectos, o presente trabalho tem como objetivo analisar os sentidos atribuídos por usuários homens sobre o atendimento que lhes é prestado no âmbito da atenção básica à saúde, buscando subsidiar a construção de indicadores qualitativos de satisfação em relação ao uso desses serviços por usuários masculinos.

Este estudo é parte de uma pesquisa multicêntrica, submetida inicialmente ao Comitê de Ética da instituição proponente (CEP/UNIFESP n. 0032/07), que objetivou investigar como se dá a relação homens-assistência à saúde nos seguintes estados: Pernambuco (nas cidades de Olinda e Recife), Rio de Janeiro (na cidade do Rio de Janeiro), Rio Grande do Norte (na cidade de Natal) e São Paulo (nas cidades de São Paulo e Santos), campos codificados como $\mathrm{PE}, \mathrm{RJ}, \mathrm{RN}$ e SP, respectivamente. A pesquisa foi financiada pelo Conselho Nacional de Desenvolvimento Científico e Tecnológico (CNPq), tendo como referência a proposta de avaliação a partir da triangulação de métodos, na qual foram consideradas na coleta de dados a observação etnográfica, entrevistas semiestruturadas, grupos focais e estudo de prontuários e os registros da produção dos serviços (COUTO et al., 2009). 
Em cada um dos campos da pesquisa, trabalhou-se com uma amostra de conveniência de serviços conforme critérios do projeto da pesquisa. Dentre eles, destacam-se o fato de o serviço ter grande volume de atendimento igual ou maior que mil atendimentos/mês), tempo de funcionamento de pelo menos 10 anos, possuir equipe multiprofissional, atender homens e ser porta de entrada da rede pública.

\section{Material e método}

Especificamente neste estudo, em termos de referencial teórico-metodológico, trabalhou-se com a perspectiva de construção de indicadores qualitativos, entendidos como aqueles que são construídos a partir da interpretação e julgamento dos próprios sujeitos envolvidos na avaliação (ASSIS et al., 2005).

Os usuários - sujeitos deste estudo - foram convidados a participar da pesquisa durante semanas típicas de atendimento, na ocasião em que usavam o serviço ou a partir de indicação dos profissionais. Tomaram-se como base os princípios de amostra em pesquisa qualitativa, considerando sujeitos em número suficiente para que fosse possível a saturação de sentidos, prevendo-se a possibilidade de haver inclusões sucessivas de sujeitos até que fosse possível uma discussão densa das questôes da pesquisa (MINAYO, 2006). Além disso, partiu-se da proposta inicial de se selecionar 20 entrevistas por serviço de atenção básica, buscando assegurar a presença de homens nas seguintes faixas etárias: 15 a 25 anos, 26 a 45 e 46 a 65. Em cada cidade, o total de entrevistas ficou em torno dos números previstos. Dois serviços participantes se diferenciavam pelo atendimento ambulatorial, sendo um deles exclusivamente voltado para adolescentes. Nesses serviços, projetaram-se, inicialmente, 10 entrevistas. No conjunto da pesquisa, trabalhou-se com 201 homens, que receberam o código do campo de pesquisa, para garantir o anonimato.

Neste estudo, foram focalizadas as seguintes questões das entrevistas semiestruturadas da pesquisa: (a) Em sua opinião, como deve ser um atendimento? (b) Você gosta de ser atendido neste serviço? Por quê? (c) Você indicaria este serviço para outro homem? Por quê? (d) O que você recomendaria para que o serviço melhor atendesse aos usuários masculinos? 
Em termos de tratamento qualitativo das respostas a essas questóes, utilizou-se o método de interpretação de sentidos, baseando-se em princípios hermenêuticodialéticos, em que o pesquisador se vale da dialética "pergunta-resposta" e interage com os resultados encontrados de modo a "fundir horizontes" relativamente às questôes de estudo e às obtidas na investigação realizada para construir um novo discurso ao interpretar o discurso que examina (MINAYO, 2002; AYRES, 2005), compreendendo o contexto, as razões e as lógicas de falas, ações e inter-relações entre grupos e instituiçôes (GOMES et al., 2005; GOMES, 2007). A análise envolveu os seguintes passos: (a) visão do conjunto e apreensão das particularidades do material da pesquisa; (b) identificação de sentidos atribuídos ao atendimento por parte dos entrevistados; (c) elaboração de indicadores qualitativos de bom atendimento a partir dos depoimentos; (d) comparação entre esses indicadores e as opiniōes dos entrevistados acerca do atendimento a homens em geral; (e) elaboração de síntese interpretativa, procurando articular objetivo do estudo, marco teórico-conceitual de satisfação, dados empíricos e resultados de outros estudos.

Esses passos foram realizados, inicialmente, com as informações coletadas no campo RJ, que foram analiticamente trabalhadas em outro estudo (GOMES et al., 2009). Os indicadores qualitativos dessa análise foram revistos e ampliados, a partir das entrevistas dos outros campos de pesquisa, para dar conta da diversidade de cidades. Uma vez definido o conjunto de indicadores, percorreuse para os demais campos a mesma trajetória analítica do estudo referente ao campo RJ, selecionando-se do total da entrevista as respostas dadas às questôes já mencionadas.

\section{Resultados e discussão}

\section{Sujeitos do estudo}

No conjunto dos 201 entrevistados (tabela 1), predominam as seguintes características sociodemográficas: faixa etária de 26 a 45 anos (36,8\%), cor branca (35,5\%), ensino fundamental completo (33,3\%), trabalhadores empregados e/ ou autônomos $(62,2 \%)$ e estado civil casado $(38,8 \%)$. Na caracterização, foram utilizados - como base para os quesitos raça/etnia, escolaridade, trabalho e estado civil - os critérios de coleta do Instituto Brasileiro de Geografia e Estatística (IBGE). 
Tabela 1 - Distribuição percentual dos entrevistados por características sociodemográficas e campo de estudo

\begin{tabular}{|c|c|c|c|c|c|}
\hline \multirow[b]{2}{*}{$\begin{array}{l}\text { CARACTERÍSTICAS } \\
\text { SOCIODEMOGRÁFICAS }\end{array}$} & \multicolumn{4}{|c|}{ CAMPO DE ESTUDO } & \multirow[b]{2}{*}{$\begin{array}{l}\text { TOTAL } \\
(\mathrm{N}=\mathbf{2 0 1})\end{array}$} \\
\hline & $\begin{array}{c}\mathrm{PE} \\
(\mathrm{N}=48)\end{array}$ & $\begin{array}{c}\mathrm{RJ} \\
(\mathrm{N}=50)\end{array}$ & $\begin{array}{c}\mathrm{RN} \\
(\mathrm{N}=63)\end{array}$ & $\begin{array}{c}\text { SP } \\
(\mathrm{N}=40)\end{array}$ & \\
\hline $\begin{array}{l}\text { Faixa etária } \\
15 \text { a } 25 \text { anos } \\
26 \text { a } 45 \text { anos } \\
46 \text { a } 67 \text { anos }\end{array}$ & $\begin{array}{l}23,4 \\
57,4 \\
19,2 \\
\end{array}$ & $\begin{array}{l}24,0 \\
24,0 \\
52,0\end{array}$ & $\begin{array}{l}32,2 \\
30,5 \\
37,3 \\
\end{array}$ & $\begin{array}{l}27,5 \\
37,5 \\
35,0 \\
\end{array}$ & $\begin{array}{l}27,0 \\
36,8 \\
36,2 \\
\end{array}$ \\
\hline $\begin{array}{l}\text { Raça/cor (autorreferida) } \\
\text { Branca } \\
\text { Parda } \\
\text { Preta } \\
\text { Sem informação }\end{array}$ & $\begin{array}{c}0,0 \\
0,0 \\
0,0 \\
100,0\end{array}$ & $\begin{array}{r}76,0 \\
18,0 \\
6,0 \\
0,0\end{array}$ & $\begin{array}{c}35,5 \\
48,4 \\
3,2 \\
12,9\end{array}$ & $\begin{array}{c}27,5 \\
20,0 \\
2,5 \\
50,0\end{array}$ & $\begin{array}{c}35,5 \\
23,5 \\
3,0 \\
38,0\end{array}$ \\
\hline $\begin{array}{l}\text { Estado civil } \\
\text { Casado } \\
\text { Divorciado } \\
\text { Solteiro } \\
\text { Viúvo } \\
\text { União estável } \\
\text { Separado } \\
\text { Sem informação } \\
\end{array}$ & $\begin{array}{c}37,5 \\
2,1 \\
31,2 \\
0,0 \\
25,0 \\
4,2 \\
0,0 \\
\end{array}$ & $\begin{array}{c}40,0 \\
4,0 \\
50,0 \\
0,0 \\
6,0 \\
0,0 \\
0,0 \\
\end{array}$ & $\begin{array}{c}44,4 \\
3,2 \\
30,1 \\
0,0 \\
17,5 \\
1,6 \\
3,2 \\
\end{array}$ & $\begin{array}{c}30,0 \\
0,0 \\
30,0 \\
2,5 \\
27,5 \\
10,0 \\
0,0\end{array}$ & $\begin{array}{c}38,8 \\
2,5 \\
35,3 \\
0,5 \\
18,4 \\
3,5 \\
1,0 \\
\end{array}$ \\
\hline $\begin{array}{l}\text { Trabalho } \\
\text { Empregado e autônomo } \\
\text { Empresário } \\
\text { Aposentado } \\
\text { Desempregado } \\
\text { Licença médica } \\
\text { Estudante e estagiário } \\
\text { Sem informação }\end{array}$ & $\begin{array}{c}64,6 \\
0,0 \\
4,2 \\
14,6 \\
0,0 \\
8,3 \\
8,3 \\
\end{array}$ & $\begin{array}{c}52,0 \\
2,0 \\
16,0 \\
4,0 \\
4,0 \\
20,0 \\
2,0 \\
\end{array}$ & $\begin{array}{c}55,5 \\
0,0 \\
9,5 \\
15,9 \\
1,6 \\
12,7 \\
4,8 \\
\end{array}$ & $\begin{array}{c}82,5 \\
0,0 \\
2,5 \\
7,5 \\
5,0 \\
2,5 \\
0,0 \\
\end{array}$ & $\begin{array}{c}62,2 \\
0,5 \\
8,5 \\
10,9 \\
2,5 \\
11,4 \\
4,0 \\
\end{array}$ \\
\hline $\begin{array}{l}\text { Escolaridade } \\
\text { Alfabetizado } \\
\text { Analfabeto } \\
\text { Ensino supletivo } \\
\text { Fundamental completo } \\
\text { Fundamental incompleto } \\
\text { Médio completo } \\
\text { Médio incompleto } \\
\text { Superior completo } \\
\text { Superior incompleto }\end{array}$ & $\begin{array}{c}0,0 \\
0,0 \\
0,0 \\
35.4 \\
18,7 \\
39,6 \\
4,2 \\
0,0 \\
2,1\end{array}$ & $\begin{array}{c}0,0 \\
0,0 \\
6,0 \\
30,0 \\
4,0 \\
46,0 \\
0,0 \\
8,0 \\
6,0\end{array}$ & $\begin{array}{c}4,8 \\
7,9 \\
0,0 \\
20,6 \\
22,2 \\
17,5 \\
22,2 \\
0,0 \\
4,8\end{array}$ & $\begin{array}{c}0,0 \\
0,0 \\
0,0 \\
55,0 \\
20,0 \\
12,5 \\
7,5 \\
5,0 \\
0,0\end{array}$ & $\begin{array}{c}1,5 \\
2,5 \\
1,5 \\
33,3 \\
16,4 \\
28,9 \\
9,4 \\
1,5 \\
5,0\end{array}$ \\
\hline
\end{tabular}

Com o conjunto desses usuários, o estudo consegue abordar uma boa diversidade em características sociodemográficas e, mesmo assim, constatase que, em termos de modelos culturais, eles apresentam similaridades que perpassam até mesmo os diferentes contextos regionais dos estados estudados.

\section{Sentidos atribuídos ao bom atendimento}

Com base em Esperidião e Trad (2005), partiu-se da premissa de que o entendimento dos critérios que os usuários utilizam para definir um bom ou um mau atendimento é fundamental para se compreender as bases da satisfação 
desses usuários acerca dos serviços. Em geral, os usuários atribuíram os seguintes sentidos ao bom atendimento: atendimento atencioso, atendimento ancorado na comunicação, atendimento que faz algo e prontidão do atendimento (tabela 2), os quais não se diferenciam pelas faixas etárias. Esses sentidos - que refletem modelos culturais - podem ser utilizados como parâmetro para a construção de indicadores qualitativos de avaliação do atendimento que é prestado a esses usuários (ASSIS et al., 2005). Tais indicadores podem servir para discutir se os serviços estão conseguindo atender às expectativas dos homens usuários, segundo a ótica deles próprios.

\section{Tabela 2: Referenciais de avaliação dos usuários (indicadores qualitativos)}

\begin{tabular}{|c|c|c|}
\hline Indicadores & Descritores & Depoimentos ilustrativos \\
\hline $\begin{array}{l}\text { Atendimento } \\
\text { atencioso }\end{array}$ & $\begin{array}{l}\text { Atendimento "atencioso" e } \\
\text { "respeitoso". Ainda que esse } \\
\text { parâmetro se refira ao tratamento } \\
\text { dispensado pelos serviços em geral, é } \\
\text { no médico que esse foco incide. }\end{array}$ & $\begin{array}{l}\text { "Um atendimento pra você [...] ser bem recebido" (usuário/PE) } \\
\text { "Eu creio que a primeira coisa que deve ter é um respeito pela pessoa humana, em } \\
\text { muito dos casos não há esse respeito." (usuário/RJ). } \\
\text { "[Um atendimento] mais atencioso" (RN) } \\
\text { "Primeiramente que te trate bem }[. . .] \text { somos todos humanos [...] então um pouco } \\
\text { de respeito com a pessoa, tanto da nossa parte como da parte dos profissionais" } \\
\text { (usuário/SP). }\end{array}$ \\
\hline $\begin{array}{l}\text { Atendimento } \\
\text { ancorado na } \\
\text { comunicação }\end{array}$ & $\begin{array}{l}\text { Atendimento que se baseia na } \\
\text { conversa e não se reduza ao ato de } \\
\text { informar. Trata-se de uma conversa } \\
\text { em que tanto médico quanto usuário } \\
\text { ora fale, ora escute, a partir de uma } \\
\text { compreensão mútua. }\end{array}$ & $\begin{array}{l}\text { "Um atendimento }[\mathrm{em}] \text { que haja oportunidade para o paciente poder relatar tudo } \\
\text { aquilo que ele tá necessitando [...] e o profissional ouvir o paciente com paciência } \\
{[\ldots] \text { uma comunicação }[\mathrm{em}] \text { que os dois ficarão entendendo o que se passou ali }} \\
\text { naquela sala." (usuário/RJ). } \\
\text { "[Que haja] uma comunicação direta do pessoal" (usuário/RN). }\end{array}$ \\
\hline $\begin{array}{l}\text { Atendimento } \\
\text { que faz algo }\end{array}$ & $\begin{array}{l}\text { Atendimento que resolve o problema, } \\
\text { com base na capacidade de quem } \\
\text { atende e na disponibilidade do } \\
\text { remédio necessário. }\end{array}$ & $\begin{array}{l}\text { "[...] que resolva o problema }[\ldots] \text { se não tiver condição de resolver }[\ldots] \\
\text { encaminha pra outro lugar" (usuário/PE). } \\
\text { "Ter o remédio que a gente precisa" (usuário/RN). } \\
\text { "Uma canseira e ai não vão te examinar direito }[\ldots] \text { eles te dão o remédio sabendo } \\
\text { que você näo vai melhorar" (usuário/SP). }\end{array}$ \\
\hline $\begin{array}{l}\text { Prontidão do } \\
\text { atendimento }\end{array}$ & $\begin{array}{l}\text { Prontidão do atendimento estrutura- } \\
\text { se principalmente a partir do desejo } \\
\text { de que o tempo entre procura por } \\
\text { atendimento e a efetivação do mesmo } \\
\text { seja o menor possível. }\end{array}$ & $\begin{array}{l}\text { "Você morre e você não é consultado. Então tem que ter esse intervalo de } \\
\text { atendimento [menor], quer dizer, não [tanto tempo]. Marca hoje pra ser } \\
\text { atendido em três meses, entendeu? Têm os exames, os exames também você marca } \\
\text { [para] daqui três meses e pra pegar o resultado de um a dois meses" (usuário/RJ). } \\
\text { "Que o atendimento fosse melhor, fosse mais rápido"(usuário/RN). } \\
\text { "Eu acho que é o seguinte: deveria vir aqui marcar, por exemplo, se você vem de } \\
\text { manhä, marcar consulta pra de tarde ou se você chega aqui sete horas, marcar } \\
\text { uma consulta para nove" (usuário/SP). }\end{array}$ \\
\hline
\end{tabular}

Os sentidos atribuídos pelos usuários ao bom atendimento - aqui vistos como indicadores qualitativos de satisfação com o atendimento prestado - se articulam direta ou indiretamente com a Teoria Centrada naSatisfação do Paciente(ARAGON, 2003; ARAGON; GESELL, 2003), bem como com taxonomias elaboradas para se avaliar a satisfação de usuários de serviços de saúde (ESPERIDIÂO; TRAD, 2005). Em geral, esses sentidos também se articulam com a Política Nacional de 
Humanização $(\mathrm{PNH})$, que concebe atendimento humanizado como aquele que, entre outros aspectos, se baseia na escuta qualificada, ampliação dos processos comunicacionais e resolutividade (BRASIL, 2004).

Esses sentidos, em geral, revelam uma ancoragem na relação médico-usuário, constituindo importante referencial para os usuários opinarem positiva ou negativamente acerca do atendimento que lhes é prestado. A positividade atribuída a essa relação não só pode resultar no aumento da satisfação dos usuários, como também pode exercer influências diretas para o estado de saúde desses sujeitos (CAPRARA; RODRIGUES, 2004).

A valorização tanto do atendimento atencioso quanto da comunicação por parte desses sujeitos - de certa forma - caminha na mesma lógica de estudos que tratam a qualidade do atendimento nos serviços de saúde, tendo como indicador a relação médico-paciente (FRANCO; CAMPOS, 1998). Esses estudos destacam que a satisfação dos pacientes se volta muito mais para o trato humanitário, a relação com o profissional e a informação recebida do que para o ato técnico em si. Aprofundando essa vertente interativa, considera-se que a relação estabelecida entre profissionais de saúde e usuário se ancora predominantemente na ótica do ato médico como rede de conversaçôes (TEIXEIRA, 2003).

Compreender a lógica que os usuários utilizam para definir o que é um bom atendimento, perpassada por diferentes ethos, tanto pode servir como ponto de partida para uma abordagem antropológica em que se põem em diálogo as diferenças entre os modelos médicos e populares de saúde (ATKINSON, 1993), como para problematizar a reprodução da cultura assistencial dominante.

\section{A ótica dos usuários sobre o atendimento dos serviços}

Em geral, observou-se uma coerência entre os parâmetros mencionados para o que é um bom atendimento e os depoimentos que avaliam o atendimento dos serviços. Esses parâmetros tanto eram usados para expressar a satisfação como a insatisfação por parte dos usuários em relação ao atendimento que lhes era prestado.

A seguir - a título de ilustração -, destacam-se alguns depoimentos que mostram que o atendimento é positivamente avaliado pelos usuários quando esse vai ao encontro daquilo que julgam ser um bom atendimento:

Gostei. $\mathrm{O}$ atendimento está sendo rápido. Eu vim marcar uma consulta hoje de manhã e hoje de manhã mesmo eu fui atendido e já fui liberado. (usuário/PE). 
Gosto [do atendimento] por causa de que eles tratam as pessoas muito bem aqui,

deixam as pessoas muito livre para expor a sua opinião. É um lugar muito bom para ser atendido. (usuário/RJ).

Geralmente o atendimento aqui é bom. O material humano aqui é bom. (usuário/RN).

Quando eu quero vir aqui, converso com o médico [...] nunca tive poblema nenhum. (usuário/SP).

Faz-se necessário observar que a avaliação positiva por parte dos usuários necessariamente não quer dizer que houve uma avaliação crítica acerca do atendimento. Há estudos de avaliação que chamam a atenção para o fato de a satisfação ser influenciada pela comparação com a precariedade de acesso vigente (SILVA et al., 2002).

Caminhando na mesma coerência entre o que se espera e como se avalia o atendimento, a avaliação negativa dos serviços de saúde por parte dos usuários pode ser ilustrada pelos seguintes depoimentos:

Não vejo nada de positivo [...] poderia ser bem melhor [...] porque a gente vê tanta gente precisando por aí [...] e a saúde precária do jeito que ta. E você vê que o governo ele investe dinheiro em tanta coisa e que sobra, mas... se você olhar direitinho. Aí a saúde deixa pra lá, que eles não dão nenhum valor. (usuário/PE).

Em geral, amigo, acho que é muito deficiente aqui [...] o atendimento, porque é muito corrido [...] [O médico] não dá a atenção necessária que nós precisamos [...] com relação ao atendimento de funcionário [...] a má vontade [...] impera [...] É ruim porque a gente chega tudo sorrindo, querendo agradar, mas não tem jeito não... (usuário/RJ)

Reclamando por causa da demora, mas eles dizem que não podem fazer nada, que não é por eles, [é] por causa de muita gente [...] Se as pessoas abordar assim pra falar desse assunto eles ficam mais fechados. (usuário/RN).

Hoje eu cheguei aqui sete e meia da manhã e fui chamado onze, quase meio dia e para vir só uma recomendação. Eu não gostei não. Preferia ter ficado em casa. (usuário/SP).

Nas avaliações negativas, a diversidade de aspectos colocados perpassa desde a referência à necessidade de um investimento político prioritário na saúde que garanta o acesso universal ao sistema de atenção, até a referência ao tensionamento relacionado a qualidades do acesso e da recepção pelos serviços dos usuários e suas demandas. Neste último aspecto, têm-se os exemplos da "demora no atendimento", relacionada ao longo período de tempo nas filas para ser atendido e ao longo intervalo entre marcação de atendimento e a resolutividade do problema que gerou a busca do atendimento. Estes aspectos das 
avaliações negativas surgiram reincidentemente nos campos de pesquisa, fazendo eco com as conclusōes do processo avaliativo 2004-2006 do Programa Nacional de Avaliação dos Serviços de Saúde (PNASS), que destaca insatisfação com o tempo de espera para se conseguir atendimento (BRASIL/MS, 2007).

Ao se aprofundar as opiniōes negativas sobre os serviços, não se pode deixar de lembrar que as reclamaçôes sobre a demora para ser atendido e a falta de medicamentos nos serviços apontam para problemas que necessariamente não são de responsabilidade direta dos profissionais que prestam os cuidados nos serviços, como dificuldades de se equacionar a oferta dos serviços com a demanda.

Contrastando-se as opiniōes positivas e negativas dos usuários acerca do atendimento, de certa forma, observam-se contradições, como entre a necessidade de prontidão convivendo paralelamente com o desejo de maior atenção e cuidado durante a consulta.

A satisfação e a insatisfação - baseadas no que se considera como bom atendimento - serviram também como parâmetro para os entrevistados justificarem sua indicação daquele serviço para outros usuários:

Não [indicaria] porque tem gente que trabalha nisso, é muito nervoso, alvoroçado. (usuário/PE).

[Indicaria] porque aqui [...] você é atendido muito bem [...] você pode expressar as suas opiniōes [...] respeitam a gente... (usuário/RJ).

[Indicaria] porque fui bem atendido e é mais rápido do que nos outros lugares que eu já passei. (usuário/SP).

Interessante trazer um depoimento segundo o qual, embora o atendimento não fosse o que o usuário desejava ter, ele indicaria para outras pessoas:

Indicaria [porque] quanto mais pessoas comparecer [...] iria melhorar bastante o atendimento. (usuário/SP).

Essa fala pode ser vista como um argumento de que o atendimento melhora na medida em que mais pessoas participem dos serviços, reivindicando seus direitos de serem atendidas.

Entre as recomendações que os usuários fizeram para sanar os problemas do atendimento, destacaram-se as relacionadas a uma maior oferta de atendimento, atenção por parte do profissional, facilidade na marcação de consultas e remuneração dos profissionais de saúde para que pudessem oferecer uma melhor assistência. 
Especificamente em relação ao atendimento de usuários homens, destacam-se as seguintes recomendações:

Uma boa campanha publicitária pra os homens prestarem mais atenção em sua própria saúde. (usuário/PE).

Na parte, por exemplo, de urologia, não tem especialista nessa parte e a parte de sexologia também, de problemas ligados à impotência, disfunção erétil, essas coisas que não parece, mas [risos] atormenta bastante os homens [...] Eu não encontrei serviço especializado pra isso. Eu encontrei até médico que me orientava e tal, mas não um especialista, uma sexóloga, um psicólogo [...] Então, se o homem precisar ele não tem... (usuário/RJ).

Uma sala pras mulheres e uma sala pros homens porque ficando junto os dois não presta. (usuário/RN).

Eu tinha vergonha de ser atendido, dependendo do assunto, ser atendido por mulher [...] que nem, por exemplo, você mostrar as suas partes íntimas às vezes pra mulher. Eu ficava com vergonha. (usuário/SP).

Esses e outros depoimentos indicam sobretudo que um atendimento para homens deve: (a) se relacionar a campanhas e reuniōes de esclarecimentos; (b) ocorrer em espaços separados do atendimento de mulheres e crianças; e (c) envolver assistência especializada, tais como psicológica, sexológica e urológica. No conjunto das recomendações, observa-se certa polêmica entre os entrevistados no que diz respeito ao fato de um atendimento a ser prestado aos homens ser realizado por um profissional do sexo masculino. Entre as opiniōes acerca do fato, destacam-se três posicionamentos: o atendimento deve ser feito pelo profissional do mesmo sexo do usuário; o atendimento a ser prestado ao homem também pode ser feito por uma mulher e o atendimento de homem para homem deveria ocorrer só em alguns casos que envolvesse a exposição de partes íntimas do corpo.

$\mathrm{O}$ primeiro e o terceiro posicionamentos trazem à tona a ideia de que há assuntos de mulheres e assuntos de homens. No que tange à temática da sexualidade, emergem anseios de se escolher quem deve participar da "conversa de homem" e da "conversa de mulher", revelando uma prática de homens serem socializados para falar da mulher e não com a mulher (GOMES et al., 2011).

\section{Considerações finais}

Embora tenham apontado algumas especificidades para seu atendimento enquanto homens, muito do que os usuários idealizam sobre o bom atendimento e o que reivindicam para que sejam mais bem atendidos pode servir para se 
discutir o atendimento de mulheres também. Ademais, conceituando-se gênero como referente sócio-histórico que, baseado nas diferenças entre os sexos, estrutura material e simbolicamente a vida social e estabelece entre homens e mulheres, ou entre pares de cada qual, relações de valor desigual, com o domínio histórico do masculino (SCOTT, 1995), diversos problemas por eles apontados e muitas das suas recomendações não se inserem apenas na ordem da construção social de gênero, mas no campo dos direitos dos cidadãos em geral. Também se observou que, neste estudo, houve uma preponderância maior de questôes acerca das diferenças de gênero do que daquelas relativas às diferenças de geração, embora homens de distintas faixas etárias tenham sido entrevistados.

Ao se focalizar as recomendações sobre como deve ser o atendimento de homens é que se percebe a perspectiva de gênero estruturando as opinióes. Mais do que defender ou não atendimentos específicos para homens e mulheres, o presente estudo revela que - devido à socialização de homens e mulheres em geral ocorrer de forma tão segmentada - são reforçadas as diferenças entre o ser usuário homem e ser usuário mulher. Por outro lado, ao se completar este estudo com outro resultante da pesquisa maior (GOMES et al., 2011), tanto no que tange aos profissionais quanto aos usuários, essa mesma segmentação por gênero pode contribuir para que se acirrem as impossibilidades de se lidar com as especificidades de homens e mulheres, em termos de demandas da saúde.

Por último, cabe destacar alguns aspectos limitantes deste particular estudo. Por se tratar de uma discussão atual e ainda pouco investigada, observa-se a necessidade de outros estudos para que se ultrapasse o estágio ainda inicial sobre o tema, em diferentes clientelas de serviços de saúde. Outro aspecto é o fato de que o presente estudo se apoia em um recorte de uma pesquisa maior, valendose a análise da satisfação dos usuários de dados produzidos para questôes mais amplas da relação entre masculinidade e saúde. Nesse sentido, não se buscou, originalmente, estabelecer uma escala de satisfação segundo a percepção dos usuários, bem como fazer comparações dos graus de satisfação entre os sítios pesquisados. O caráter de primeiro estudo de satisfação de usuários masculinos poderá contribuir para a elaboração de futuras investigações que articulem a dimensão de gênero com a problemática da qualidade do acesso e da recepção dos usuários nos serviços. 


\section{Referências}

ARAGON, S.J. Commentary: a patient-centered theory of satisfaction. American Journal of Medical Quality, v.18, n. 6, p. 225-228, 2003.

ARAGON, S.J.; GESELL, S.B. A patient satisfaction theory and its robustness across gender in emergency departments: a multigroup structural equation modeling investigation. American Journal of Medical Quality, v. 18, n. 6, p. 229-241, 2003.

ASSIS, S.G.; DESLANDES, S.F., MINAYO, M.C. de S. et al. Definição de objetivos e construção de indicadores visando à triangulação. In: MINAYO, M. C. de S.; ASSIS, S.G.; SOUZA, E.R. (Org.). Avaliação por triangulação de métodos: abordagem de programas sociais. Rio de Janeiro: Fiocruz, 2005. p. 105-32.

ATKINSON, S.J. Anthropology in research on the quality of health services. Cad. Saude Pública, Rio de Janeiro, v. 9, n. 3, p. 283-299, 1993.

AYRES, J.R.C.M. Hermenêutica e humanização das práticas de saúde. Ciência \& Saúde Coletiva, Rio de Janeiro, v. 10, n. 3, p. 549-560, 2005.

BOSI, M.L.M.; AFFONSO, K.C. Cidadania, participação popular e saúde: com a palavra, os usuários da Rede Pública de Serviços. Cad. Saúde Pública, Rio de Janeiro, v. 14, n. 2, p. 355-365, 1998.

BRASIL. Ministério da Saúde. Programa Nacional de avaliação dos Serviços: resultado do processo avaliativo 2004-2006. Brasília: Ministério da Saúde, 2007.

BRASIL. Ministério da Saúde. Secretaria-Executiva. Núcleo Técnico da Política Nacional de Humanização. HumanizaSUS: Política Nacional de Humanização. A humanização como eixo norteador das práticas de atenção e gestão em todas as instâncias do SUS. Brasília: Ministério da Saúde, 2004.

CAPRARA, A.; RODRIGUES, J. A relação assimétrica médico-paciente: repensando o vínculo terapêutico. Cienc. Saúde Coletiva, Rio de Janeiro, v. 9, n. 1, p. 139-146, 2004.

CASTILLO, L.; DOUGNAC, A.; VICENTE, I. et al. Los predictores de satisfacción de pacientes en un centro hospitalario universitario. Rev.Med.Chile, v. 135, p. 696-701, 2007.

COUTO, M.T.; SCHRAIBER, L.B.; GOMES, R. et al. Saúde da população masculina na atenção primária: tendência histórica e representações sobre necessidades, acesso e uso de serviços em cidades de quatro estados do Brasil (RN, PE, RJ, SP). Relatório Final de Pesquisa. Brasília: CNPq, 2009.

ESPERIDIĀO, M.; TRAD, L.B.A. Avaliação de satisfação de usuários. Ciênc. Saúde Coleti$v a$, Rio de Janeiro, v. 10, n. 0, p. 303-312, 2005.

FIGUEIREDO, W. Assistência à saúde dos homens: um desafio para os serviços de atenção primária. Ciênc. Saúde Coletiva, Rio de Janeiro, v. 10, n. 1, p. 105-109, 2005. 
FRANCO, S.C.; CAMPOS, C.W. S. Avaliação da qualidade de atendimento ambulatorial em pediatria em um hospital universitário. Cad. Saúde Pública, Rio de Janeiro, v. 14, n. 1, p. 61-67, 1998.

GOMES, R. Análise e interpretação de dados de pesquisa qualitativa. In: MINAYO, M.C. de S.(Org.). Pesquisa social: teoria, método e criatividade. Petrópolis: Vozes, 2007. p. 79-108.

GOMES, R.; SOUZA, E.R.; MINAYO, M. C. de S. et al. Organização, processamento, análise e interpretação de dados: o desafio da triangulação. In: MINAYO, M.C. de S.; ASSIS, S.G.; SOUZA, E.R. (Org.). Avaliação por triangulação de métodos: abordagem de programas sociais. Rio de Janeiro: Fiocruz, 2005. p. 185-221.

GOMES, R.; MOREIRA, M.C.N.; NASCIMENTO, E.F. et al. Os homens não vêm! Ausência e/ou invisibilidade masculina na atenção primária. Ciênc. Saúde Coletiva, Rio de Janeiro, v. 16, supl. 1, p. 983-992, 2011.

GOMES, R.; NASCIMENTO, E.F.; ARAÚJO, F.C. Por que os homens buscam menos os serviços de saúde do que as mulheres? As explicações de homens com baixa escolaridade e homens com ensino superior. Cad Saude Publica, v. 23, n. 3, p. 565-74, 2007.

GOMES, R.; REBELLO, L.E.F.S.; NASCIMENTO, E.F. et al. A atenção básica à saúde do homem sob a ótica do usuário: um estudo qualitativo em três serviços do Rio de Janeiro. Ciênc. Saúde Coletiva [periódico na internet]. 2009. Disponível em: http://www.abrasco.org. br/cienciaesaudecoletiva/artigos/artigo_int.php?id_artigo=3686. Acesso em: 15 maio 2009.

MINAYO, M.C. de S. O desafio do conhecimento: pesquisa qualitativa em saúde. São Paulo: Hucitec, 2006. 406p.

MINAYO, M.C.de S. Hermenêutica dialética como caminho do pensamento social próprio. In: MINAYO, M.C.de S.; DESLANDES, S. F. (Org.). Caminhos do pensamento. Epistemologia e método. Rio de Janeiro: Fiocruz, 2002. p. 83-107.

OLIVEIRA, A.K.P.; BORGES, D.F. Programa de Saúde da Família: uma avaliação de efetividade com base na percepção de usuários. RAP, Rio de Janeiro, v. 42, n. 2, p. 369-389, 2008.

PINHEIRO, R.S.; VIACAVA, F.; TRAVASSOS, C. et al. Gênero, morbidade, acesso e utilização de serviços de saúde no Brasil. Ciênc. Saúde Coletiva, Rio de Janeiro, v. 7, p. 687707, 2002.

SCOTT, J. Gênero: uma categoria útil para a análise histórica. Educação e realidade, v. 20, n. 2, p. 71-99, 1995.

SILVA, A.M.R.; ANDRADE, S.M.; THOMSOM, Z. Opiniões de mães de crianças que morreram no primeiro ano de vida no Município de Londrina, Paraná, Brasil. Cad. Saúde Pública, Rio de Janeiro, v. 18, n. 5, p. 1295-1302, 2002. 
TEIXEIRA, R.R. O acolhimento num serviço de saúde entendido como uma rede de conversações. In: PINHEIRO, R.; MATTOS, R.A.(Org.). Construção da Integralidade: cotidiano, saberes e práticas em saúde. Rio de Janeiro: IMS-UERJ, 2003. p. 89-111.

TRAD, L.A.B.; BASTOS, A.C.S.; SANTANA, E.M. Estudo etnográfico da satisfação do usuário do Programa de Saúde da Família (PSF) na Bahia. Ciênc. Saúde Coletiva, Rio de Janeiro, v. 7, n. 3, p. 581-589, 2002.

VAITSMAN, J.; ANDRADE, G.R.B. Satisfação e responsividade: formas de medir a qualidade e a humanização da assistência à saúde. Ciênc. Saúde Coletiva, Rio de Janeiro, v. 10, n. 3, p. 599-613, 2005. 


\section{Men's public health care: a qualitative study in four Brazilian federal states}

This study aims to analyze the meanings attributed by male users to the health care provided to them by the primary health care. It also tries to hook up the construction of qualitative indicators of satisfaction with the use of such services by males. For this purpose, a qualitative study was conducted, involving semistructured interviews with 201 users from four Brazilian federal states. The data has been analyzed under the method of interpretation of meanings inbuilt in hermeneutic-dialectical principles. As for the results, users were asked to point toward criteria to evaluate positively the services, taking as reference a communicative and attentive service, as long as it makes a difference to them as well as bring up readiness. As a conclusion, it was found that male users outlook the services through rose-tinted glasses and therefore claim a particular form of care grounded on that assumption. Moreover, this conclusion could also be used to discuss the health care of women as well. On the other hand, due to the socialization that men and women experience, differences between male and female users could be reinforced. Conversely, regarding to both professionals and users, this gender segmentation may add to bring about the impossibilities of dealing with the specifics of men and women in terms of public health care demands.

> Key words: User's satisfaction; men's health; men; primary health care. 